\title{
Caminho de volta
}

\section{Resumo}

O artigo analisa a trajetória da autora no campo do teatro em comunidades e a experiência do projeto de extensão em teatro, atualmente por ela coordenado, no Complexo da Maré, Rio de Janeiro, à luz da teoria da ação cultural dialógica proposta por Paulo Freire. O texto também aborda as relações entre teatro e comunidades no âmbito dos projetos artísticos e sociais desenvolvidos nas favelas do Rio de Janeiro e implementados pelas organizações não governamentais (ONGs), investigando, especialmente, o papel do "artista facilitador".

Palavras-chave: Ação cultural; Teatro em comunidades; Extensão.

\section{Abstract}

This paper traces the research of this writer in the area of community theatre including her current work as coordinator of the extension theatre project in the Maré Complex, Rio de Janeiro, employing the theories of Paulo Freire concerning dialogical cultural action. The paper also deals with the relationship between theatre and communities in the area of social development and artistic projects implemented by Non-Governmental Organizations (NGOs) in the favelas of Rio de Janeiro, with special attention given to the role of the 'artist facilitator'.

Key words: Cultural Action; Community Theatre; Field work

Sábado, 9h da manhã, um grupo de estudantes da Universidade Federal do Estado do Rio de Janeiro (UNIRIO) se prepara para ocupar a van que todas as semanas parte da universidade em direção ao conjunto de favelas conhecido como Complexo da Maré, no Rio de Janeiro. Lá, quatro grupos de adolescentes aguardam os estudantes para mais uma "manhã de teatro". O trajeto entre a universidade e a Maré deixa para trás a visão dos cartões postais da zona sul carioca para seguir a Av. Brasil, endereço das dezesseis comunidades que compõem o complexo.

O caminho é o mesmo que percorri em meados da década de noventa, quando um projeto de teatro de minha autoria foi aprovado por um programa social que naquela década, de plena expansão do terceiro setor ${ }^{1}$, financiou muitas iniciativas

\footnotetext{
${ }^{1} \mathrm{O}$ "Terceiro Setor" é composto de organizações sem fins lucrativos criadas e mantidas pela ênfase na participação voluntária, num âmbito não governamental, dando continuidade às práticas tradicionais da caridade, da filantropia e do mecenato e expandindo o seu sentido para outros domínios, graças, sobretudo, à incorporação do conceito de cidadania e de suas múltiplas manifestações na sociedade civil.
} 
no Rio de Janeiro e também em outras capitais do país. Na época, a aprovação do projeto foi mais do que uma surpresa, um susto. Recém formada como atriz e jornalista, eu havia estado na Maré apenas uma vez para conversar com uma associação de moradores, que apreciou a ideia trazida pela moça "da universidade": criar um núcleo de teatro para adolescentes. A experiência de dois anos na comunidade do Parque União, uma das que integram a Maré foi definitiva, descobri um novo sentido para a minha vida no teatro.

Depois dela sugiram outras, em diferentes favelas da cidade. Isto porque as ações nas quais me engajei faziam parte do contexto que o Rio de Janeiro viveu na década de noventa, quando ocorreu uma verdadeira explosão de projetos sociais implementados pelas organizações não governamentais (ONGs), que apostavam no teatro, e também nas outras artes, como uma alternativa para a melhoria da qualidade de vida de crianças e jovens. Os resultados alcançados por alguns desses projetos, bem como a sua crescente divulgação nos veículos de comunicação, afirmou a ideia de que as linguagens artísticas exercem uma influência poderosa sobre crianças e adolescentes, representando um contraponto para enfrentar e combater a violência. Diversas iniciativas espalhadas pela cidade do Rio, e outras também pelo país, reconheceram a arte, o esporte, a educação e a cultura como:

Um elemento estratégico para enfrentar e combater a violência (...) um incentivo aos jovens para afastarem-se de situações de perigo, sem lhes negar meios de expressão e de descarga dos sentimentos de indignação, protesto e afirmação positiva de suas identidades (CASTRO, 2001, p.19).

O fenômeno ajudou a redesenhar o campo que chamamos de educação não formal e contribuiu também com mudanças na área da Pedagogia do Teatro. Maria Lúcia Pupo reconhece a multiplicação das iniciativas que têm levado o "fazer e fruir" teatral a espaços diversificados, além da escola:

\footnotetext{
Demandas de entidades as mais variadas, tanto ligadas à sociedade civil quanto às ONGs, quanto instituições ligadas ao poder público na área da cultura como é o caso de centros culturais, alem de setores da área de saúde, constituem algumas das múltiplas esferas nas quais os processos de criação em teatro - e de modo mais abrangente, nas artes da cena - revelam uma área em plena expansão (PUPO, 2008, p.59).
}

As experiências teatrais destacadas pela professora envolvem pessoas "comuns", grupos de não-atores, como atuantes e espectadores. Segundo ela, essas iniciativas estão inseridas em uma noção ampla de educação "baseada no princípio de que as ações interativas entre os indivíduos promovem a construção de saberes" (PUPO, 2008, p.60). São exemplos que atestam um quadro singular, no qual coletivos teatrais revelam 
uma "notável capacidade de intervenção na vida social. (...) O teatro transborda das margens que até há pouco pareciam conter o seu percurso." (PUPO, 2008, p.61)

Diante do contexto que se apresentou nos anos 90 , e que ganhou força na década seguinte, percebi a oportunidade de aliar a arte que eu havia escolhido como profissão e o trabalho comunitário; junto com isso, bem aflorada naquela fase de minha juventude, a sede de "mudar o mundo". Mas, não precisou muito tempo para que, além do entusiasmo, eu começasse também a formular importantes perguntas: qual seria o meu papel ou contribuição ali, inserida naquela realidade, tão diferente da minha? Haveria uma maneira especial de pessoas como eu, artista "de fora", se relacionar com as comunidades? Que fatores teriam contribuído com a construção de uma imagem que vê a favela como um território à parte da cidade, nicho da desordem, da carência, da violência? Quais estratégias desenvolveram essas comunidades para sobreviver aos problemas estruturais provocados pela negligência do Estado? Por que o contexto sóciopolítico e econômico da década de 90 favorecia um verdadeiro boom do chamado terceiro setor e dos projetos promovidos pelas organizações não governamentais (ONGs)? Por que o discurso da "responsabilidade social" ganhou tanta força nas propagandas das grandes empresas, tendência que se intensificou ainda mais nos últimos anos? Mas, sobretudo, me indaguei sobre que teatro fazer, que teatro colocar em cena? O desejo de procurar respostas para essas questões motivou o meu retorno à universidade para desenvolver as pesquisas de mestrado e doutorado. ${ }^{2}$

Em 2010, após seis anos na pós-graduação, ingressei como professora no Departamento de Ensino do Teatro da UNIRIO e logo providenciei um novo encontro com a favela. O projeto de extensão Teatro em comunidades - Redes de Teatro na Maré acontece a partir de uma parceria firmada entre a UNIRIO e a Redes de Desenvolvimento da Maré (REDES) ${ }^{3}$. O projeto, coordenado por mim, inclui a participação de

\footnotetext{
${ }^{2}$ As pesquisas resultaram na dissertação: Nós do Morro: percurso, impacto e transformação. O grupo de teatro da favela do Vidigal. Programa de Pós-Graduação em Teatro (UNIRIO), 2005. Orientador: Prof.Dr. Zeca Ligiero. E na tese: A favela como palco e personagem e o desafio da comunidade-sujeito. Programa de Pós-graduação em Artes Cênicas (UNIRIO), 2010. Orientação: Profa.Dra. Beatriz Resende; Coorientação: Profa. Dra. Márcia Pompeo Nogueira.(UDESC).

${ }^{3}$ No momento, o projeto inclui nove estudantes, entre eles: voluntários, bolsistas de extensão, cultura, pesquisa e permanência. A Redes de Desenvolvimento da Maré é uma organização da sociedade civil que se dedica a promover a construção de uma rede de desenvolvimento sustentável, voltada para a transformação estrutural do conjunto de favelas da Maré; busca produzir conhecimento referente aos espaços populares e realizar ações com o intuito de interferir na lógica de organização da cidade e contribuir para a superação das desigualdades. Mais informações disponíveis em: www.redesdamare.org.br
} 
estudantes da graduação em Teatro da UNIRIO, a maioria deles do curso de Licenciatura em Teatro, que orientam as atividades em núcleos de teatro em diferentes pontos do Complexo da Maré. Atualmente o projeto acolhe quatro grupos, cada um deles com cerca de 20 adolescentes. As atividades ocorrem nos seguintes espaços: dois na comunidade de Nova Holanda (sede da REDES e no Centro de Artes da Maré), um na comunidade de Nova Maré (Lona Cultural Hebert Vianna) e outro em Ramos, no auditório do Centro Municipal de Saúde Américo Veloso. Os licenciandos trabalham em duplas e trios e são responsáveis pela orientação dos trabalhos práticos desenvolvidos nos núcleos de teatro.

Agora, acompanhada por meus alunos, faço o caminho de volta ao lugar onde tudo começou com o desafio de alcançarmos, como nos lembra Paulo Freire, a unidade dialética entre teoria e prática. Pois, como ele afirma: "Separada da prática, a teoria é puro verbalismo inoperante: desvinculada da teoria, a prática é ativismo cego" (FREIRE, 2001, p.158). Para fugir do equívoco do "ativismo cego" a experiência na extensão tem se revelado um rico terreno para a investigação científica. E minha vivência, enquanto docente na universidade, um espaço para a efetiva articulação entre pesquisa, ensino e extensão.

Os anos dedicados à pesquisa contribuíram com a formação de um olhar mais crítico em relação à prática que eu desenvolvia nos anos noventa, quando comecei a atuar no campo, hoje reconhecidos pelo meio acadêmico brasileiro como do teatro em comunidades ou ação cultural e, em outras partes do mundo, como o do teatro aplicado, applied theatre. ${ }^{4}$ Embora cada uma dessas nomenclaturas apresente formulações teóricas próprias, não é difícil identificar entre elas algumas características comuns: são práticas que acontecem longe do âmbito das salas tradicionais de espetáculo, além do território do mainstream, ou do teatro comercial; que levam o teatro a determinadas comunidades, que envolvem a participação de pessoas comuns, suas histórias, lugares, desejos, prioridades e que são motivadas pelo desejo político de transformar, por meio do teatro, realidades individuais e coletivas.

Os professores Márcia Pompeo Nogueira e Tim Prentki por meio de diversas publicações nos últimos anos vêm colaborando com a compreensão deste universo

\footnotetext{
${ }^{4}$ O termo teatro em comunidades vem sendo utilizado pela Profa. Márcia Pompeo Nogueira em diversas publicações. Como Nogueira, venho optando pelo seu uso, embora também seja corrente no campo da Pedagogia do Teatro o termo ação cultural. Já o termo teatro aplicado (applied theatre) ganhou destaque no cenário internacional e é investigado com mais profundidade em minha tese de doutorado.
} 
aqui em nosso país. De acordo com Prentki, professor pesquisador britânico, as práticas do teatro aplicado acontecem, quase sempre: "Em espaços informais, em lugares não-teatrais, numa variedade de ambientes geográficos e sociais: rua, prisões, centros comunitários, conjuntos habitacionais, ou qualquer outro lugar que possa ser específico ou relevante aos interesses da comunidade" (PRENTKI, 2009, p. 9). Em semelhante definição para teatro em comunidades, Nogueira explica que:

Trata-se de um teatro criado coletivamente, através da colaboração entre
artistas e comunidades específicas. Os processos criativos têm sua origem
e seu destino voltados para realidades vividas em comunidades de local ou
de interesse. De um modo geral, mesmo usando terminologias diferentes,
esboça-se um método baseado em histórias pessoais e locais, desenvolvidas
a partir de improvisação. Cada terminologia, a seu modo, guarda relações
com um processo educativo entendido ou não como transformador. Do meu
ponto de vista podemos, no Brasil, chamar essas práticas de Teatro em
Comunidades (NOGUEIRA, 2008, p.4).

De acordo com Márcia Pompeo os processos de criação na área do teatro em comunidades envolvem a maior parte das vezes a "interação entre artistas da classe média e pessoas de comunidades periféricas" (NOGUEIRA, 2009, p. 181). O tipo de interação, como aponta a autora, exige o enfrentamento de muitas questões, especialmente a que se refere à atitude do artista facilitador $^{5}$ em relação aos grupos comunitários. Neste ponto cabe destacar a importância que assume a pedagogia freireana no campo do teatro em comunidades, reconhecida também como suporte teórico pelos estudos na área desenvolvidos fora do Brasil. Em sua teoria da ação dialógica Freire argumenta a favor de ações nas quais "os sujeitos se encontram para transformação do mundo em co-laboração" (FREIRE, 2002, p.165) e condena as práticas baseadas na perspectiva da "conquista", que implicam "um sujeito que, conquistando o outro, o transforma em quase coisa" (FREIRE, 2002, p.165).

Ainda segundo Freire, a co-laboração, a união, a organização e a síntese cultural, elementos constitutivos da teoria da ação cultural dialógica, garantem o encontro de sujeitos para a "pronúncia do mundo, para a sua transformação" (FREIRE, 2002, p. 166). Pronunciar o mundo, ou nomear o mundo significa para o educador devolver ao homem a sua responsabilidade histórica - o homem como sujeito que elabora o mundo, que emerge do lugar de mero objeto para assumir o papel de autor crítico e consciente da história.

\footnotetext{
${ }^{5} \mathrm{O}$ termo facilitador é assumido por vários estudos realizados no campo do applied theatre, e aparece com muita frequência nas publicações em língua inglesa como facilitator. Em minha tese de doutorado acrescentei a ele a palavra artista, como o intuito de dar ênfase ao fato de que os processos desenvolvidos por esses indivíduos incluem a parceria entre a pedagogia e a arte.
} 
O papel dos artistas facilitadores assume neste processo grande importância. De fato, este tem sido um dos temas mais frequentes nos debates travados em sala de aula, quando analisamos a prática dos estudantes junto aos grupos de jovens na Maré. O esforço tem sido em provocá-los a refletir sobre a política que permeia a sua prática na extensão, os instigando a buscar respostas para as perguntas que no passado eu mesma me fiz: Quais são as nossas intenções ao desenvolver o trabalho na Maré? A quem interessa mais o "projeto"? Até que ponto a nossa ação assegura a participação e a autonomia dos grupos envolvidos? São questões que nos convidam a pensar sobre o que difere a ação cultural para a liberdade, e outros tipos de ação que alimentam a dependência e a dominação.

Nos últimos vinte anos nos acostumamos com as campanhas anuais da televisão, em que crianças, em destaque as negras, sorridentes aparecem ao lado de slogans de importantes logomarcas solicitando doações em prol de um futuro melhor e repleto de esperança para a infância e juventude brasileiras. No país entregue ao modelo neoliberal, a súbita generosidade dos empresários é flagrada nos slogans "nós fazemos a nossa parte" ou "somos uma empresa cidadã" que se destacam nas publicidades institucionais, tentando nos convencer de que a "responsabilidade social" das empresas resolverá os problemas estruturais que são, a priori, tarefa do Estado.

Não são poucos os artistas, práticos, professores de teatro que trabalham nos "projetos" promovidos pelas ONGs, sustentados, a maior parte das vezes, pelas empresas "cidadãs". Durante muitos anos atuando neste campo senti o desconforto de constatar o conflito entre a minha crença no potencial do teatro de acolher o homem como "transformador aquele que é capaz de intervir nos processos da natureza e nos da sociedade, que não encara o mundo apenas como é, mas que se faz senhor dele" (BRECHT, 1967, p.138) e as intenções dos projetos para os quais trabalhava, agentes de manipulações sutis, mais empenhados na permanência do que na mudança. $O$ mesmo assunto é levantado por Suzana Viganó, quando argumenta sobre a relação entre as ONGs e o mercado:

O discurso e a prática assistencial das ONGs e do terceiro setor, quando servem à ideologia e à ordem econômica dominantes não são capazes de propor um verdadeiro processo democrático, mas apenas um consenso. $E$ isso não é suficiente para alterar os rumos da ordem vigente (VIGANÓ, 2006, p.48).

O dilema é o mesmo: de um lado as intenções do agente cultural, e o seu desejo de realizar a ação "compreendida sob uma perspectiva educacional emancipatória, capaz de desenvolver a consciência estética e a capacidade crítica” (VIGANÓ, 2006, p. 17); de outro 
a ação de grupos hegemônicos que utilizam a arte como "instrumento paliativo de controle social" (VIGANÓ, 2006, p.16). O agente cultural terá que conviver com o dolorido paradoxo: como preservar nosso projeto transformador que pretende dar voz à cultura dominada se, a rigor, estamos inseridos na estrutura do "projeto" da cultura dominante?

Hoje, como professora na universidade, busco compartilhar com os estudantes este dilema experimentado por mim e também por Suzana. Para ilustrá-lo, costumo resgatar as imagens que nos oferece Paulo Freire sobre as "mãos em gestos de súplica" e "mãos que trabalham e transformam o mundo". Os gestos de súplica estendidos aos opressores, "falsamente generosos, que têm a necessidade, para que a sua generosidade continue tendo oportunidade de realizar-se, da permanência da injustiça” (FREIRE, 2002, p.31). Em contrapartida, argumenta Freire:

\section{A grande generosidade está em lutar para que, cada vez mais, estas mãos, sejam de homens ou de povos, se estendam menos, em gesto de súplica. Súplica de humildes a poderosos. E se vão fazendo, cada vez mais, mãos humanas, que trabalhem e transformem o mundo (FREIRE, 2002, p.31).}

O desejo de participar de uma "missão transformadora" implica perigosas armadilhas para os artistas facilitadores. Não queremos estender nossas mãos aos gestos de súplica, mas instaurar a verdadeira generosidade, trabalhando em verdadeiro diálogo com os grupos comunitários. É preciso estar atento ao fato de que mesmo as ações da universidade sobre a sociedade, podem facilmente assumir o caráter de projeto colonizador, nos quais os "missionários evoluídos" penetram nas favelas para "assistir", "atender" ou "ajudar" seres desafortunados a sair das trevas e ganhar a luz por meio do teatro. Embora a imagem esteja mudando nos últimos anos, a instituição universidade sempre foi vista pelas classes populares como um reduto da elite, onde os filhos das classes média e alta se preparam para obter os postos mais privilegiados na sociedade. Todo cuidado é pouco, pois como enfatiza Paulo Freire a ação cultural, ou está a "serviço da dominação - consciente ou inconscientemente por parte de seus agentes - ou está a serviço da libertação dos homens." (FREIRE, 2002, p. 179)

No "caminho de volta" à Maré o desafio tem sido instaurar por meio do encontro entre os estudantes da UNIRIO e os jovens das comunidades um processo, não um projeto. Um espaço onde o teatro, por meio da força da narrativa dramática, estabeleça um processo no qual os jovens da Maré se tornem sujeitos de seu próprio desenvolvimento. O palco como um lugar que favorece a reinvenção da vida na cena, em que a realidade se transforme em objeto de reflexão e criatividade, um espaço para a expressão de um novo discurso, de uma outra palavra. 
Mais uma vez recorro à sabedoria de Paulo Freire:

Enquanto a ação cultural para a libertação se caracteriza pelo diálogo, a ação cultural para a domesticação procura embotar as consciências. A primeira problematiza; a segunda "sloganiza". Desta forma, o fundamental na primeira modalidade de ação cultural, no próprio processo de organização das classes dominadas, é possibilitar a estas a compreensão crítica da verdade de sua realidade (FREIRE, 2001, p.95).

No caso da experiência deste projeto de extensão, a "compreensão crítica da verdade de sua realidade," sobre a qual argumenta Freire, ganha uma dupla dimensão, um duplo valor. Ao mesmo tempo em que estabelecemos como meta promover processos teatrais em que as "classes dominadas" possam construir o seu próprio discurso sobre a realidade, questionando-a, expressando-a com sua voz e seu corpo; também nós, no retorno semanal à universidade, nos encontros de planejamento e avaliação das ações propostas em campo, nos colocamos em estado de alerta e crítica sobre as nossas atitudes. Para os estudantes, a maior parte deles futuros educadores em teatro, cabe um aviso especial:

\begin{abstract}
A tendência de trabalhar com aqueles que são vítimas da maneira como o mundo é dirigido, em vez daqueles que dirigem o mundo, pode tentar o teatro ao território do terapeuta, encorajando participantes a se adaptar mais efetivamente ao mundo, em vez de imprimir suas cores no mastro da mudança social, através do encorajamento da análise e ações que buscam adaptar o mundo às necessidades e direitos da maioria das espécies. Ao trilhar o caminho da inclusão social os facilitadores podem facilmente encontrar-se operando como o braço (leve) da política governamental, representando a sociedade civil e as parcerias do setor voluntário. Aparentemente, as iniciativas democráticas, podem tropeçar facilmente na domesticação, em situações onde o poder de definir a agenda e de agir sobre ela não foi dividido com os participantes (PRENTKI, 2009, p.30).
\end{abstract}

Em outras palavras, torna-se imprescindível um constante questionamento sobre o intuito da "missão transformadora" e as armadilhas que nela possam estar escondidas. Sejam as ações propostas pelas ONGs, pelas universidades ou por outros tantos atores sociais que hoje tecem uma complexa rede de sociabilidades, os artistas, estudantes, professores de teatro trabalhando neste campo precisam desenvolver um estado crítico permanente sobre o seu papel dentro dos "projetos", assumindo a atitude investigativa, perguntadora, tão defendida por Bertolt Brecht: Afinal em que projetos desejam se engajar? A que tipo de política em relação às comunidades se pretende aderir? Que valores regem determinados projetos e porque participar deles? Até que ponto determinadas ações indicam algum comprometimento com a cultura da mudança? Ou ainda, que tipo de teatro se pretende fazer e colocar em cena?

Não há receita para escapar de equívocos, mas é provável que o hábito de fazer perguntas para a realidade possa evitá-los com mais frequência. Minha tarefa enquanto 
docente na universidade, articulando junto com meus alunos a tríade extensão, ensino e pesquisa, tem sido alertá-los sobre a necessidade de superar a compreensão ingênua do mundo. A mesma tarefa lhes cabe junto aos jovens da Maré.

Todos os sábados no retorno à universidade, são alegres as notícias que os estudantes trazem sobre os trabalhos com os grupos de adolescentes. A van para nos quatro espaços onde ocorrem as atividades e recolhe os estudantes. Mais uma "manhã de teatro" acontecera, nos despedimos da Maré e dos jovens, tomamos o caminho de volta à UNIRIO deixando para trás o cenário das ruelas das favelas em direção à Av. Brasil e depois à bucólica zona sul da cidade maravilhosa. Para mim este percurso tem sido emocionado, porém atento, pois como não nos deixa esquecer Bertolt Brecht:

É certo que vivem num tempo negro. Veem o homem como um brinquedo. Nas mãos de forças ruins. Sem preocupação vive apenas o tolo. Destinado à ruína. Está o ingênuo.

\section{Referências bibliográficas}

BRECHT, Bertolt. O Teatro Dialético. Rio de Janeiro: Civilização Brasileira, 1967.

Poemas 1913-1956. Seleção e trad. Paulo César Souza. São Paulo: Editora Brasiliense, 3a. Ed., 1987.

CASTRO, Mary. Cultivando Vida, desarmando violências. Brasília: UNESCO, Brasil Telecom, Fundação Kellogg, Banco Interamericano de Desenvolvimento, 2001.

COUTINHO, Marina Henriques. A favela como palco e personagem e o desafio da comunidadesujeito. Tese de Doutorado (2010). Programa de Pós-Graduação em Artes Cênicas da Universidade Federal do Estado do Rio de Janeiro - UNIRIO.

FREIRE, Paulo. Pedagogia do Oprimido. Rio de Janeiro: Paz e Terra, 32ª. ed., 2002.

Ação cultural para a liberdade e outros escritos. Rio de Janeiro, 9a.ed., 2001.

NOGUEIRA, Márcia Pompeo. Teatro em comunidades, questões de terminologia. ANAIS do $\checkmark$ Congresso da ABRACE, 2008. Disponível em: http://www.portalabrace.org/vcongresso/ progpedagogia.html (arquivo pdf)

Teatro e Comunidade. In: FLORENTINO, Adilson e TELLES, Narciso. (Orgs.) Cartografias do Ensino do Teatro. Uberlândia: EDUFU, 2009. p. 173-183.

PUPO, Maria Lúcia de Barros. Dentro ou fora da escola? In: URDIMENTO - Revista de Estudos em Artes Cênicas - Especial. UDESC. Programa de Pós-graduação em Teatro. - vol. 1, n.10 (dez, 2008) - Florianópolis: UDESC/CEART. Anual. p. 59-64

PRENTKI,Tim and PRESTON, Sheila. (orgs.) The Applied Theatre reader. London and New York: Routledge, 2009.

VIGANÓ, Suzana Schmidt. As regras do jogo: a ação sócio-cultural em teatro e o ideal democrático. São Paulo: Hucitec, 2006. 